\title{
REDES METALORGÂNICAS E SUAS APLICAÇÕES EM CATÁLISE
}

\author{
André Luis Dantas Ramos*\#,a, Stefania Tanase ${ }^{\mathrm{b}}$ e Gadi Rothenberg ${ }^{\mathrm{b}}$ \\ a Departamento de Engenharia Química, Universidade Federal de Sergipe, Av. Marechal Rondon, S/N, B. Jardim Rosa Elze, \\ 49100-000 São Cristóvão - SE, Brasil

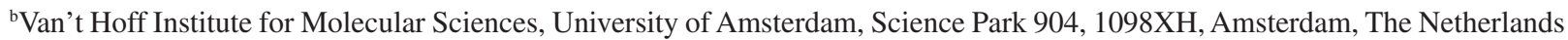

Recebido em 28/05/2013; aceito em 26/07/2013; publicado na web em 21/08/2013

\begin{abstract}
METAL-ORGANIC FRAMEWORKS AND THEIR APPLICATIONS IN CATALYSIS. Metal-organic frameworks (MOFs) form a new class of materials with well-defined yet tunable properties. These are crystalline, highly porous and exhibit strong metal-ligand interactions. Importantly, their physical and chemical properties, including pore size, pore structure, acidity, and magnetic and optical characteristics, can be tailored by choosing the appropriate ligands and metal precursors. Here we review the key aspects of synthesis and characterization of MOFs, focusing on lanthanide-based and vanadium-based materials. We also outline some of their applications in catalysis and materials science.
\end{abstract}

Keywords: carboxylate linker; lanthanide; vanadium.

\section{INTRODUÇÃO}

Desde a primeira metade do século XIX, a partir dos estudos de Berzelius, os catalisadores são investigados pela comunidade científica e aplicados em diversos processos industriais. Ao longo da evolução dos estudos da Catálise, a introdução de técnicas de caracterização superficiais, a modelagem molecular e o desenvolvimento de métodos de síntese avançados transformaram a preparação de catalisadores de uma arte à base da tentativa e erro (a partir do conhecimento químico e experiência do pesquisador) em uma ciência multidisciplinar que permite o projeto molecular de catalisadores sólidos específicos para determinada aplicação. Destacam-se o desenvolvimento na síntese de zeólitas, "zeotypes" e materiais mesoporosos, que permitiram a introdução, identificação e otimização de sitos ativos bem definidos (prótons, ácidos de Lewis, redox) na estrutura destes materiais. ${ }^{1}$

No entanto, as dimensões dos poros das zeólitas e zeotypes limitavam as reações para moléculas com tamanho inferior a $1 \mathrm{~nm}$, até a descoberta de zeólitas com poros maiores, na faixa dos mesoporos. Mesmo assim, algumas reações são limitadas nestes materiais pelo tamanho dos poros incompatíveis com moléculas como triglicerídeos e metaloporfirinas. Além disso, o controle e modulação das propriedades eletrônicas dos sítios ativos da rede ainda é muito limitado em comparação aos catalisadores à base de complexos de metais de transição. Esses problemas foram um pouco contornados com o desenvolvimento de materiais mesoporosos, mas os resultados ainda são limitados.

Nesse contexto, surgem os polímeros de coordenação, que combinam as funcionalidades de seletividade de poros e a modulação de propriedades eletrônicas dos organometálicos. Eles podem ser definidos como uma extensa rede de íons ou agrupamentos (clusters) metálicos coordenados a moléculas orgânicas multidentadas, em dimensões porosas bem definidas. ${ }^{1}$

As redes metalorgânicas (metal organic frameworks-MOFs) pertencem a uma nova classe de polímeros de coordenação com desenvolvimento bem recente que alia três características: cristalinidade,

*e-mail: aldramos@ufs.br

\# Endereço atual (Pós-Doutorado): Van't Hoff Institute for Molecular Sciences, University of Amsterdam, Science Park 904, 1098XH, Amsterdam, The Netherlands alta porosidade e existência de forte interação metal-ligante orgânico. ${ }^{2}$ $\mathrm{Na}$ sua síntese pode-se modular tanto a estrutura porosa quanto as propriedades eletrônicas do sítio ativo, escolhendo cuidadosamente o ligante orgânico ou o modificando com tratamentos pós-síntese, mostrando grande potencial de aplicação industrial no século XXI, em especial na fabricação de produtos químicos e na química fina. Em termos de porosidade, as MOFs preenchem uma lacuna entre as zeólitas microporosas e silicatos mesoporosos. Quimicamente, os MOFs têm potencial para preencher a lacuna entre as zeólitas e as enzimas, pois podem ter três características: sítios polinucleares isolados, interação específica sítio ativo-substrato e um ambiente da cavidade com hidrofobicidade ajustável.

Em especial, as MOFs à base de lantanídeos têm grande potencial para catálise heterogênea, visto que os íons lantanídeos têm uma esfera de coordenação flexível, tornando possível criar centros metálicos coordenativamente insaturados, com canais 1D de alta estabilidade térmica. Destacam-se também as MOFs à base de vanádio, para reações de oxidação parcial, em especial a epoxidação. Cientistas consideram que o desenvolvimento das MOFs ainda está na sua infância, em especial sua aplicação em reações catalíticas e processos industriais, ${ }^{3}$ visto que há vários desafios tecnológicos a serem superados com base no desenvolvimento científico.

O presente artigo pretende abordar alguns aspectos da síntese e caracterização das MOFs e revisar as suas principais aplicações, especialmente catalíticas. Um enfoque especial será dado às MOFs à base de lantanídeos e vanádio.

\section{HISTÓRICO DAS REDES METALORGÂNICAS}

Polímeros de coordenação são conhecidos há décadas. Primeiramente, em 1954, Wells ${ }^{4}$ introduziu o conceito de estruturas cristalinas inorgânicas, onde os íons metálicos, agindo como nós, ligam-se entre si através de um espaçador (spacer), tais como as moléculas orgânicas multidentadas dos polímeros de coordenação. A topologia da rede resultante depende da geometria e do ambiente de coordenação dos nós, sendo o espaçador apenas uma conexão linear entre nós adjacentes. ${ }^{5}$

Um outro trabalho pioneiro registrado sobre polímeros de coordenação critalinos foi o de Kinoshita et al., ${ }^{6}$ em 1959, descrevendo a estrutura do composto de cobre com adiponitrila e ânions nitrato. 
No entanto, nada foi discutido sobre a porosidade do material e, embora mais alguns trabalhos tenham sido publicados na década de 60, pouca atenção foi dada ao tema. Por volta de 1989, a partir do trabalho de Hoskins e Robson sobre redes poliméricas constituídas por segmentos tridimensionais com unidades de conexão tipo haste, em especial o composto $\left\{\mathrm{Cu}^{\mathrm{I}}\left[\mathrm{C}\left(\mathrm{C}_{6} \mathrm{H}_{4} \cdot \mathrm{CN}\right)_{4}\right]\right\}_{\mathrm{n}}{ }^{\mathrm{n}+}{ }^{7}$, esta classe de material foi "redescoberta". Em trabalho posterior, ${ }^{8}$ os autores mencionam o potencial uso destes materiais em Catálise, embora não tenham realizado nenhum estudo. Outros trabalhos foram publicados no início da década de $90,{ }^{9}$ sendo que a primeira aplicação catalítica, na reação de cianosililação de aldeídos, foi reportada por Fujita et al. ${ }^{10}$ em 1994 e o termo "metal-organic framework" surgiu na literatura de periódicos apenas em 1995 nos trabalhos do grupo de Yaghi, ${ }^{11}$ ressaltando-se que nenhum dos trabalhos citados mostrou dados de porosidade e pouco foco tenha sido dado para aplicações catalíticas.

Um grande avanço no estudo dos polímeros de coordenação ocorreu quando começou a se desenvolver materiais com porosidade permanente, estáveis termicamente e quimicamente e sem a presença de moléculas visitantes. ${ }^{12} \mathrm{O}$ trabalho de Li et al. ${ }^{13}$ pode ser considerado um marco no estudo das MOFs e o primeiro caso de sucesso de síntese de um polímero de coordenação de altíssima porosidade e estabilidade. Os autores sintetizaram uma MOF 3-D com grupamentos de $\mathrm{Zn}_{4} \mathrm{O}$ e ácido tereftálico como ligante, $\left[\mathrm{Zn}_{4} \mathrm{O}(\mathrm{bdc})_{3}\right.$ ], batizada de MOF-5, com uma estrutura cúbica e um sistema poroso tridimensional, área BET de $3800 \mathrm{~m}^{2} \mathrm{~g}^{-1}$, que manteve suas propriedades estruturais mesmo quando totalmente dessolvatada e aquecida até $300{ }^{\circ} \mathrm{C}$. A partir deste trabalho, várias MOFs foram sintetizadas com base neste bloco de construção, com área porosa de até $6260 \mathrm{~m}^{2} \mathrm{~g}^{-1} \cdot{ }^{14}$ Uma busca na base de dados Web of Knowledge até abril de 2013 mostra 5140 trabalhos com a palavra-chave "metal-organic framework" no título, sendo o mais antigo de 1995. Destes, 2439 trabalhos (47,5\%) foram publicados de 2011 até abril de 2013, mostrando a atualidade do tema.

\section{NOMENCLATURA E DEFINIÇÕES}

A síntese das MOFs passa pela adição de uma solução contendo o metal e outra com o componente orgânico. Ao juntar as duas, ocorre um processo de auto-arranjo (self-assembly), com os metais ou clusters formando os "nós" e a molécula orgânica as "hastes", atuando como ligante, cedendo os elétrons na ligação coordenada com o centro metálico. É possível, nessa estrutura, a presença de moléculas "visitantes" em seu interior.

Além da ligação coordenada com o ligante orgânico, os átomos de metal podem estar coordenados com outras moléculas, tais como $\mathrm{CO}_{2}, \mathrm{H}_{2} \mathrm{O}, \mathrm{Cl}, \mathrm{CN}$, etc. Existem algumas possibilidades de geometria do centro metálico, as chamadas unidades secundárias de construção (secondary building units - SBUs), que representam a forma como o metal está cooordenado. A Figura 1 mostra algumas destas SBUs. ${ }^{15}$ Segundo Eddaoudi et al. ${ }^{16}$ SBUs são complexos moleculares e grupamentos nos quais os modos de coordenação do ligante e os ambientes de coordenação do metal podem ser utilizados para a transformação destes fragmentos em redes porosas estendidas usando ligantes politópicos. Em alguns casos, a SBU é composta apenas de um átomo de metal, em um bloco de construção molecular chamado MBB (single-metal-ion-based molecular building block), que pode ser obtido in situ a partir de íons metálicos heteroquelados com ligantes multifuncionais. ${ }^{17}$ Em outros, há formação de um grupamento de átomos metálicos (cluster). Uma das mais comuns é a chamada "paddle-wheel" (haste-roda), representada na Figura 1A, onde dois átomos metálicos estão ligados a quatro grupos carboxílicos na configuração syn-syn, ${ }^{18}$ com os dois átomos de oxigênio do mesmo grupo carboxílico fazendo uma espécie de ponte com os dois átomos metálicos. Outras SBUs usuais são a unidade básica de acetato de zinco octaédrica e o trímero prisma trigonal com um átomo de oxigênio no centro. ${ }^{2}$ Tranchemontagne et al. ${ }^{19}$ apresentam uma revisão com diversas SBUs que podem ser observadas nas MOFs, com três (Ex: triângulo), quatro (Ex: paddle-wheel, tetraedro), cinco (Ex: pirâmide quadrada), seis (Ex: prisma trigonal, octaedro), oito (Ex: octógono, prisma retangular), nove, dez, onze, doze, quatorze, quinze, dezesseis, dezoito e vinte e dois pontos de extensão, sendo estes geralmente átomos de carbono.

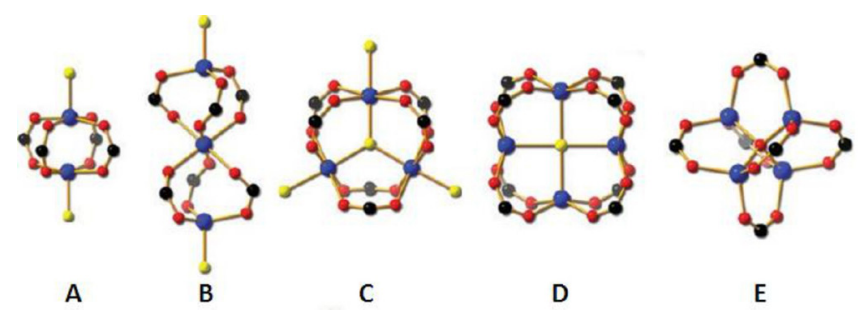

Figura 1. Unidades secundárias de construção (SBUs) comumente observadas nas redes metalorgânicas. Código de cores: preto: carbono; vermelho: oxigênio; azul: metal; amarelo: outros. (A) haste-roda (padle-wheel) binuclear; (B) ampulheta trinuclear; $(C)$ prisma trinuclear; (D) cubóide tetranuclear; (E) octaedro tetranuclear. Reimpressa com permissão de Acc. Chem. Res. 2011, 44, 123, ${ }^{15}$ Copyright 2011 American Chemical Society

Quanto ao ligante orgânico, existem diversos compostos que podem ser utilizados. A Figura 2 mostra alguns deles. Destacam-se moléculas aromáticas policarboxiladas, bipiridinas e moléculas poliazoheterocíclicas (imidazol, triazol, tetrazol, pirimidina, pirazinas etc), sendo o ácido tereftálico um dos mais utilizados. Paz et al. ${ }^{20}$ apresentam uma revisão sobre o projeto de ligantes para MOFs funcionais, mostrando a relação entre a natureza e a estrutura de ligantes orgânicos especificamente projetados e as propriedades dos produtos. A posição dos grupos de coordenação nas moléculas do ligante é muito importante para definir aonde o metal irá se coordenar e como a rede irá crescer, definindo a estrutura final da MOF.

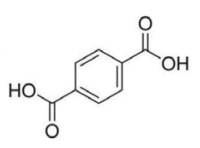

Ácido tereftálico

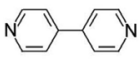

4,4'-Bipiridina

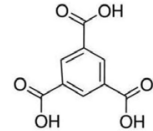

Ácido trimésico

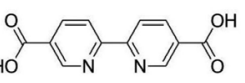

Ácido 2,2'-bipiridina-5, ' $^{\prime}$-dicarboxilico

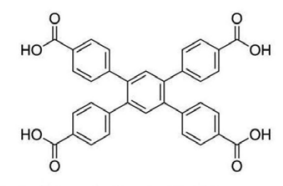

1,2,4,5-Tetraquis(4-carboxifenil)benzeno

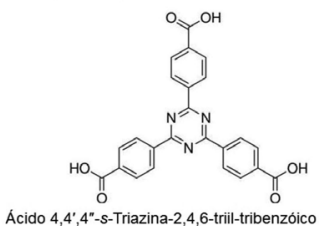

Figura 2. Ligantes (moléculas aromáticas policarboxiladas, bipiridinas e moléculas poliazoheterocíclicas) comumente utilizados na síntese de MOFs

Assim como as zeólitas, as MOFs são compostas de células unitárias que se repetem, a partir da união das duas SBUs, formando uma rede tridimensional que dá a característica de porosidade e cristalinidade à MOF. Características geométricas e químicas das SBUs levam à predição da topologia da rede. ${ }^{16}$ Por exemplo, a MOF-5 reportada por por Li et al. ${ }^{13}$ tem uma célula unitária cúbica, sendo que em cada vértice um grupamento do tipo $\mathrm{Zn}_{4}(\mathrm{O}) \mathrm{O}_{12} \mathrm{C}_{6}$ está presente, ligando-se através de uma molécula do ligante bdc, compondo as "arestas" do cubo, estrutura batizada de pcu (primitive cubic unit). Este cubo tem uma cavidade interna capaz de hospedar uma esfera de $18,5 \AA$ A. Existem várias outras estruturas de rede reportadas na base 
de dados RCSR (reticular chemistry structure resource), tais como diamante (dia), quartzo (qtz), colméia de abelha ( $6^{3}$ honeycomb), cooperita (PtS), $\mathrm{SrSi}_{2}, \mathrm{ThSi}_{2}, \mathrm{NbO}$, sodalita ( $\mathrm{sod}$ ), cúbica de corpo centrado (bcu), etc. ${ }^{16,21}$

Em termos de nomenclatura, o pouco tempo de descoberta dessa família de material e o fato de ser um campo de pesquisa multidisciplinar, envolvendo a química do estado sólido, inorgânica e de coordenação, faz com que ainda não haja uma nomenclatura padrão. Pelo contrário, há uma interposição de conceitos, terminologias e classificações. ${ }^{22}$ Por exemplo, os termos "polímeros de coordenação" e "redes metalorgânicas" muitas vezes são considerados sinôminos, ${ }^{12}$ ou que o último é um subgrupo do primeiro. ${ }^{1}$ Alguns autores consideram que, para ser MOF, deve ser provado que o material é poroso por meio de isotermas de adsorção. Outros julgam que isto não é necessário, bastando que o material tenha uma estrutura 2-D ou 3-D com ligantes orgânicos. Batten et al. ${ }^{22}$ concordam com esta última proposição e sugerem três classificações: a primeira com base na estrutura ou topologia da rede (Ex: dia-MOF, srs-MOF); a segunda com base nos componentes (Ex: carboxylate-MOF, imidazolate-MOF, anionic-MOF) e a terceira com base nas propriedades (Ex: porous-MOF, porous-CP, spin transition-MOF). No entanto, Perry IV et al. ${ }^{5}$ consideram MOF uma subclasse de polímeros de coordenação 3-D apenas.

Segundo Rowsell e Yaghi, ${ }^{2}$ é inapropriado o uso do termo MOF para materiais que foram caracterizados apenas por cristalografia, visto que é necessário que a molécula do solvente seja removida ou trocada sem a perda de integridade da rede. $\mathrm{Na}$ verdade, a síntese de estruturas abertas metal-ligante orgânico (Ex: metal-bipiridina) pode produzir muitas estruturas de rede catiônicas, mas o desafio é evitar o colapso da estrutura com a evacuação ou troca da molécula visitante. Para isto, é necessário o uso de ligantes multidentados (Ex: carboxilatos), a fim de que se forme uma estrutura rígida com ligações do tipo M-O-C. ${ }^{16}$ Kitagawa et al. ${ }^{23}$ já tinha proposto algo parecido, classificando os polímeros de coordenação em gerações: a primeira seria composta por aqueles em que a rede porosa seria sustentada por moléculas vizinhas, que colapsaria com a remoção das mesmas; a segunda seria de sistemas porosos robustos, com porosidade permanente, mesmo após a retirada de moléculas de solvente (as primeiras MOFs estariam classificadas nesta geração); e a terceira, com sistema poroso flexível, com possibilidade de mudanças reversíveis dependendo da presença de moléculas visitantes ou em resposta a estímulos externos, tais como luz, temperatura ou campos elétrico e magnético.

A IUPAC iniciou um projeto de unificação de nomenclatura em 2009, denominado "Coordination polymers and metal-organic frameworks: terminology and nomenclature guidelines”, ainda não concluído, embora haja uma recomendação provisória já publicada. ${ }^{24} \mathrm{O}$ documento define MOF como um polímero de coordenação (alternativamente rede de coordenação) com uma rede aberta (open framework) contendo espaços potenciais. Percebe-se que a IUPAC está caminhando para uma definição bem genérica, mas que deixa claro que o espaço interno precisa estar disponível e as moléculas do solvente devem estar livres para fluir e sua remoção ser testada. O documento também recomenda fortemente o uso de topologia para melhorar a descrição das estruturas dos cristais das MOFs e dos polímeros de coordenação 3-D, segundo descrito no trabalho de O'Keeffe et al. ${ }^{21}$

Até o presente momento, as MOFs têm sido batizadas com um acrônimo, seguido de um número sequencial em termos de descoberta. Os acrônimos podem indicar o tipo de material (Ex: $\mathrm{MOF}=$ metal organic framework; $\mathrm{COF}=$ covalent organic framework $; \mathrm{RPF}=$ rare earth polymeric framework), o tipo de estrutura (Ex: ZMOF=MOF com estrutura similar à uma zeólita; $\mathrm{ZIF}=$ zeolitic imidazole framework;
IRMOF=MOF isoreticular) ou o laboratório que o material foi preparado $(\mathrm{Ex}: \mathrm{CPO}=$ coordination polymer of Oslo). Uma alternativa a esta nomenclatura é o uso da fórmula empírica, expressando o(s) metal(is), o(s) ligante(s) e a estequiometria na célula unitária, podendo aparecer também a molécula "visitante". Ex: $\left[\mathrm{Zn}_{4}(\mathrm{O})(\mathrm{bdc})_{3}\right] \cdot 3 \mathrm{H}_{2} \mathrm{O}$, sendo que o oxigênio e a molécula de 1,4-benzenodicarboxilato (bdc) são ligantes e a $\mathrm{H}_{2} \mathrm{O}$ é uma molécula "visitante". ${ }^{1}$ Também é adotada uma nomenclatura em relação às dimensões da rede e sua conectividade: 0-D (molécula discreta, amorfa), 1D (filamentos), 2D (planos) e 3D (rede tridimensional). ${ }^{25}$

\section{SÍNTESE E MODIFICAÇÕES PÓS-SÍNTESE DE MOFS}

Experimentalmente, a síntese das MOFs é relativamente trivial, em temperaturas relativamente amenas (usualmente abaixo de $200{ }^{\circ} \mathrm{C}$ ), pela questão da estabilidade. Pode-se empregar até mesmo tubos de ensaio com rosca, a depender da temperatura da síntese, em condições ambientes ou solvotérmicas (solvente a quente, pressurizado), com solvente puro ou mistura. Caso temperaturas maiores sejam necessárias, comumente se utilizam recipientes (liners) de teflon inseridos em vasos de aço inoxidável. O processo normalmente ocorre em recipiente único (one pot), sendo procedido de etapas de filtração e lavagem com solvente apropriado, não sendo recomendada uma etapa de calcinação devido à baixa estabilidade térmica.

Se experimentalmente não há grandes dificuldades, a grande questão do processo da síntese é prever como ocorrerá o processo de auto-montagem (self assembly) do ligante e do centro metálico, o que exige conhecimento de química de coordenação, de estado sólido e exploração das condições reacionais. Sendo assim, a criteriosa escolha do ligante e do precursor metálico é fundamental para a obtenção de uma MOF com as características desejadas. O processo de auto-montagem acontece pela formação de ligações coordenadas entre o metal e o ligante, assim como ligações mais fracas do tipo van der Waals ou pontes de hidrogênio entre os componentes não metálicos. ${ }^{18}$ É possível preparar uma série de compostos com a mesma topologia de rede, mas diferindo apenas na natureza e tamanho do ligante, formando uma série de compostos isoreticulares. ${ }^{14} \mathrm{Uma}$ dada combinação metal-ligante também pode levar a várias estruturas diferentes, fenômeno denominado polimorfismo. ${ }^{1}$

Segundo Makiura e Kitagawa, ${ }^{26}$ a fim de obter um material de alta porosidade, deve-se ter em mente que as moléculas têm uma tendência de se agregar, em ordem de estabilizar suas interações intermoleculares. Logo, o processo de auto-montagem deve ocorrer com as moléculas se alinhando na superfície de uma forma que cada componente adota uma proximidade topológica ideal e distâncias que levam à criação de cavidades. Os autores descrevem dois métodos para preparo de MOFs 2-D: o método Langmuir-Blodgett, voltado para a fabricação de monocamadas bem ordenadas em substratos líquidos, e o método camada por camada (layer-by-layer), técnica representativa para crescimento de filme, onde um substrato sólido é utilizado para o crescimento de camadas consecutivas sobre a primeira camada formada pelo método anterior.

Segundo Edaoudi et al., ${ }^{16}$ existem duas estratégias para a síntese de estruturas rígidas porosas: uma, chamada expansão, faz o uso de ligantes longos (Ex: 4,4'-bipiridina) que aumentam o espaço entre os vértices da rede, gerando espaços vazios proporcionais ao comprimento do ligante. Assim, uma ligação é substituída por uma sequencia de ligações. O grande problema desta estratégia é a grande possibilidade de interpenetração de rede, isto é, uma malha de rede se interpõe à outra, diminuindo os espaços vazios e, consequentemente, a porosidade. Segundo os autores, as estruturas de rede com maior possibilidade de interpenetração são a cúbica, diamante e $\mathrm{SrSi}_{2}$. Por contrassenso, quanto maior o tamanho do espaço vazio de uma célula 
unitária, maior a tendência de interpenetração, embora o fenômeno não impeça a obtenção de materiais porosos abertos. Cristais com poros extralargos são naturalmente instáveis e só se estabilizam com a ocorrência do fenômeno de interpenetração ou com a inclusão de moléculas visitantes. ${ }^{27}$

A segunda estratégia, chamada decoração, envolve o uso de grupamentos metálicos (clusters) ao invés de átomos individuais nos vértices da rede. Desta forma, estes grupamentos rígidos (ex: cluster metal-carboxilato) ocupam o vértice de células unitárias (Ex: cubo) e são conectados por estruturas estáveis de ligantes politópicos (ex: anel benzênico do ligante 1,4-benzenodicarboxilato), formando uma rede rígida, aberta e sem a tendência de interpenetração.

Burnett e Choe $^{28}$ definem um processo chamado auto-montagem sequencial, no qual primeiro se sintetiza uma estrutura, que serve de modelo de partida para outras etapas do processo de auto-montagem. Eles descrevem três estratégias de síntese: inserção do ligante no modelo de partida, substituição de um ligante do modelo de partida por outro ou então remoção do ligante do modelo de partida 3-D, substituindo-o por uma molécula, formando uma MOF 2-D.

Hoskins e Robson ${ }^{8}$ introduziram o conceito de síntese de compostos polinucleares com blocos de construção (building-block approach) em 1990. Desde então, muitos autores têm utilizado este método, trazendo novas contribuições. Um exemplo é a síntese reportada por Tanase et al. ${ }^{29}$ de MOFs à base de lantanídeos. Os autores comentam que a grande esfera de coordenação dos lantanídeos faz com que não seja fácil inseri-los em uma estrutura altamente ordenada como as MOFs. Uma maneira de superar este problema é associá-los com íons metais de transição. No entanto, desta forma não é possível controlar a posição do lantanídeo na estrutura da MOF, o que, na verdade, fornece as propriedades óticas e de luminescência. Assim, os autores propuseram um método de síntese baseado na afinidade dos íons lantanídeos a ligantes contendo doadores híbridos oxigênio-nitrogênio (Ex: ácido 5-metil-2-pirazina carboxílico - Hmpca), realizando um bloco de construção de lantanídeos in situ, associando-os com $\left[\mathrm{Mo}(\mathrm{CN})_{8}\right]^{4-}$, conforme mostra a Figura 3. Dessa forma, obteve-se uma rede porosa 3-D, com interessantes propriedades magnéticas e de luminescência.
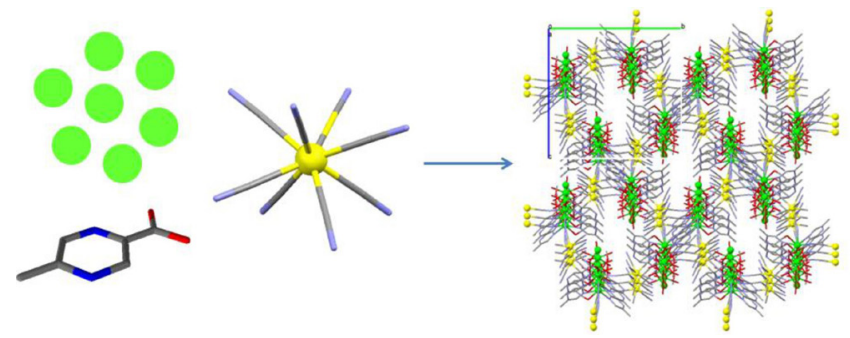

Figura 3. Síntese pelo método dos blocos de construção da MOF [Ln(mp$\left.\mathrm{Ca})_{2}\left(\mathrm{CH}_{3} \mathrm{OH}\right)_{2} \mathrm{Ln}\left(\mathrm{H}_{2} \mathrm{O}\right)_{6} \mathrm{Mo}(\mathrm{CN})_{8}\right] \cdot \mathrm{xCH}_{3} \mathrm{OH} \cdot y \mathrm{H}_{2} \mathrm{O}$. Código de cores: verde: lantanídeo; vermelho: oxigênio; amarelo: molibdênio; azul: nitrogênio; cinza: carbono. Átomos de Ln (III) estão coordenados com átomos de Mo (IV), moléculas de metanol e com o ligante orgânico 5-metil-2-pirazina carboxilato - mpca, tanto no átomo de nitrogênio quanto nos átomos de oxigênio do grupo carboxila, formando uma rede tridimensional

Algumas MOFs podem ser sintetizadas com ligantes ou moléculas de solventes passíveis de serem removidos com tratamentos pós-síntese (Ex: aquecimento). Desta forma, o sítio metálico pode ficar com uma posição de coordenação livre para agir como catalisador, sensor ou sítio de adsorção. Neste caso, a estratégia é a utilização de ligantes que se adsorvem fracamente no sítio metálico (ex: metanol, etanol) como solventes na síntese, que ficam apontados para o centro da rede, podendo se dissociar e ser evacuado dos póros, produzindo centros metálicos abertos e redes porosas. ${ }^{16}$
Para evitar o bloqueio da esfera de coordenação em torno do centro metálico pelo ligante orgânico, além da estratégia anterior, outras duas são utilizadas: ${ }^{1}$

a) Síntese de MOFS com complexos metálicos agindo como blocos de construção - são utilizados ligantes que são complexos contendo metais coordenados com ligantes orgânicos, acessíveis a moléculas visitantes. Neste caso, este metal (e não o que age como nó) ou outro grupamento do complexo podem ser ativos em reações envolvendo o centro metálico para qual se sabe que complexos homogêneos análogos são ativos;

b) Pós-funcionalização de MOFs - consiste em aplicar métodos convencionais da química orgânica (ex: sulfonação, carbonilação), modificando e funcionalizando os ligantes orgânicos ou o centro metálico, adaptando o material para aplicações específicas. Normalmente, se introduz grupos funcionais no ligante orgânico por ligação covalente ou se enxerta moléculas orgânicas nas vacâncias de coordenação dos sítios metálicos geradas após eliminação do solvente. Outra alternativa é o ligante orgânico possuir grupos de ligação (Ex: hidroxila) que não tem papel estrutural na rede e é passível de receber um átomo metálico com tratamento apropriado. ${ }^{30}$

Deve-se levar em conta que, muitas vezes, os grupos funcionais não são incorporados no ligante, mas ficam coordenados diretamente com o metal, o que não é desejável. Outro ponto que deve ser levado em conta é que o tratamento deve preservar a estrutura da MOF. Uma das funcionalizações mais empregadas é no carbono do anel aromático de MOFs que utilizam ácido tereftálico como ligante.

Um dos trabalhos pioneiros na pós-funcionalização de MOFs foi o de Wang e Cohen, ${ }^{31}$ que utilizaram MOFs com grupamentos amina (IRMOF-3) tratadas com anidrido acético, obtendo-se uma MOF de acetamida. Posteriormente os autores publicaram dois artigos de revisão, ${ }^{30,32}$ citando vários outros processos de pós-funcionalização, tais como alquilação de grupos piridínicos com haletos de alquila, oxidação do átomo de enxofre com dimetildioxirano, modificação do grupo amina da MOF-3 com 1,3-propanosultona e 2-metilaziridina, ou com salicilaldeído, seguido de metalação com vanádio, transformação do grupo amina livre em iso(tio)cianatos reativos através de reação com difosgênio ou tiofosgênio, dentre outras.

Goesten et al. ${ }^{33}$ reportaram um novo método pós-funcionalização de MOFs, visando introduzir acidez nas mesmas para aplicações em catálise, que consiste no tratamento das MOFs MIL-101 (Cr) e MIL-53 (Al), ambas tendo como ligante o ácido tereftálico, com uma mistura de anidrido trifluorometanossulfônico e ácido sulfúrico. Os autores verificaram, por infravermelho, a presença do grupo sulfoxi, com acidez de Brønsted e atividade catalítica para várias reações que exigem sítios ácidos, que serão discutidas na seção específica de catálise.

Recentemente, o método "click chemistry" se mostrou adequado para projetar MOFs sob medida, promovendo reações in situ dos grupos funcionais com alcinos. ${ }^{34}$

\section{CARACTERIZAÇÃO DE MOFS}

Sendo as MOFs materiais cristalinos de alta área superficial, as técnicas de caracterização são as usuais de materiais com estas características, tais como as zeólitas. Como a estabilidade da MOF é sempre uma preocupação, as técnicas de caracterização muitas vezes são utilizadas tanto após a síntese quanto após aquecimento e/ ou vácuo, para comprovar a manutenção das propriedades da MOF após a remoção de moléculas visitantes, por exemplo.

Uma característica importante é a estabilidade térmica da MOF. Para este monitoramento, a técnica indicada é a análise térmica gravimétrica (TGA) e diferencial (DSC). A MOF precisa mostrar 
uma perda negligível de massa entre a temperatura de dessorção da molécula visitante e o colapso da estrutura, que deve ocorrer na maior temperatura possível. ${ }^{2}$ Normalmente a técnica é utilizada sob fluxo de gás inerte (Ex: He, Ar, $\mathrm{N}_{2}$ ). Ao final do experimento, tanto moléculas visitantes quanto ligantes foram decompostos e, normalmente, a massa restante é apenas do óxido metálico. A Figura 4 mostra espectros de análise termogravimétrica da MOF $\left[\mathrm{La}(\mathrm{btb})\left(\mathrm{H}_{2} \mathrm{O}\right) \cdot 3 \mathrm{dmf}\right]$, onde btb é o ligante 1,3,5-tris(4-carboxyphenyl)benzeno, reportada por $\mathrm{Mu}$ et al. ${ }^{35}$ Nota-se que, após remoção das moléculas visitantes de dimetilformamida ( $\mathrm{dmf}$ ) e da molécula de água coordenada (de 20-325 ${ }^{\circ} \mathrm{C}$ ), o composto se mantém estável até $560^{\circ} \mathrm{C}$, podendo ser considerada uma das MOFs de lantanídeos mais estáveis reportadas na literatura. O mesmo ocorre no caso de uma troca de solvente com diclorometano e após ativação a $330^{\circ} \mathrm{C}$, o que na verdade reflete a estabilidade da MOF inicial. Vale ressaltar que a MOF ativada mostrou uma área superficial BET elevada, de $1014 \mathrm{~m}^{2} \mathrm{~g}^{-1}$.

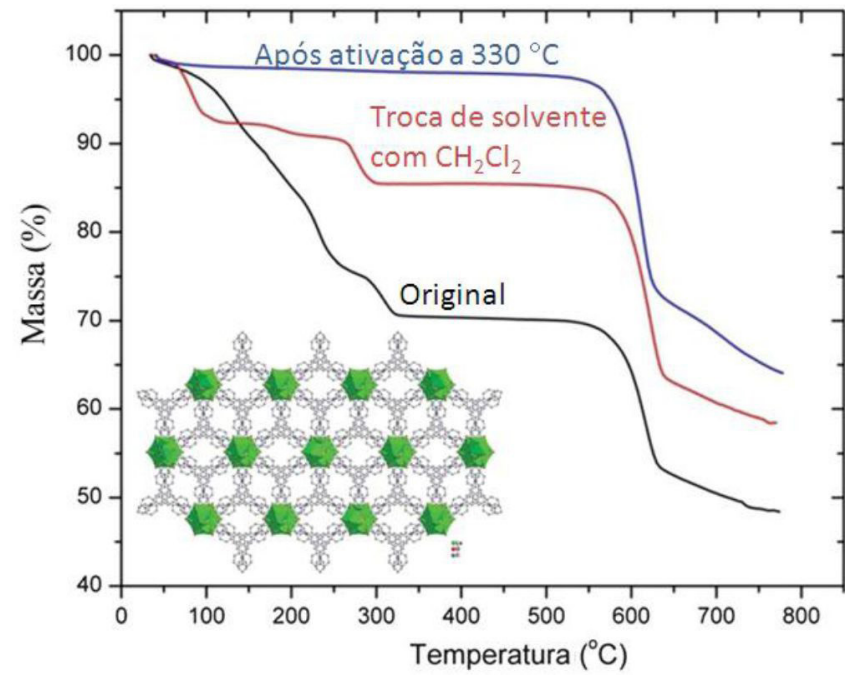

Figura 4. Análise termogravimétrica da $\mathrm{MOF}\left[\mathrm{La}(\mathrm{btb})\left(\mathrm{H}_{2} \mathrm{O}\right) .3 \mathrm{dmf}\right]_{n}$, como sintetizada e após as etapas de ativação a $330{ }^{\circ} \mathrm{C}$ e troca de solvente com diclorometano. A MOF mostra alta estabilidade térmica, mesmo após os processos de troca de solvente e ativação térmica. Adaptado da referência 35 com permissão da The Royal Society of Chemistry

Para checar se a síntese foi bem sucedida, isto é, se houve a formação da rede composta pelo centro metálico e os ligantes, a técnica de espectrometria de absorção no infravermelho pode ser empregada, para checar as bandas características do ligante. As bandas mais investigadas são as do grupo carboxilato, dos anéis imidazólico e piridínico e da hidroxila. Quanto ao grupo carboxilato, as bandas mais investigadas são a de vibração de alongamento assimétrica (em torno de 1550-1620 $\mathrm{cm}^{-1}$ ) e simétrica (em torno de $1385-1430 \mathrm{~cm}^{-1}$ ). A diferença de frequência entre estas duas bandas pode indicar se a coordenação com o ligante é bidentada (diferença em torno de $205 \mathrm{~cm}^{-1}$ ). Quanto ao anel imidazólico, existe uma banda característica da ligação $\mathrm{C}=\mathrm{N}$ em torno de $1467 \mathrm{~cm}^{-1}$, enquanto o anel piridínico é em torno de $1500-1590 \mathrm{~cm}^{-1}$. Quanto à hidroxila, a região característica de várias bandas é de $3000-4000 \mathrm{~cm}^{-1}$. 27,33,36,37 Dependendo do ligante, outras bandas específicas podem ser investigadas. Alguns autores empregam a técnica de ressonância magnética nuclear em estado sólido para checar a presença de grupos funcionais e o ambiente químico do centro metálico das MOFs, assim como a dinâmica de moléculas visitantes. ${ }^{2,33,38}$

A cristalinidade da MOF deve ser checada por difração de raios-X, tanto do pó (PXRD) quanto do monocristal, que também pode ser utilizada para verificar a pureza do composto sintetizado. A técnica, aplicada a monocristais, permite refinar (resolver) a estrutura e determinar padrões de rede (Ex: espaço d, I/I0, hkl) que auxiliam na determinação da topologia da mesma. Técnicas de microscopia, tais como a microscopia eletrônica de transmissão (TEM), também fornecem informações sobre a estrutura e cristalinidade, assim como a presença de defeitos. ${ }^{36,39}$

A Figura 5 mostra espectros de difração de raios-X (parte inferior) e de absorção no infravermelho (parte superior) da MOF MIL-71 (ou $\left.\mathrm{V}_{2}{ }_{2}(\mathrm{OH})_{2} \mathrm{~F}_{2}\left\{\mathrm{O}_{2} \mathrm{C}-\mathrm{C}_{6} \mathrm{H}_{4}-\mathrm{CO}_{2}\right\} . \mathrm{H}_{2} \mathrm{O}\right)$ sintetizada por Barthelet et al. ${ }^{40}$ Esta MOF tem uma estrutura tridimensional que consiste de camadas construídas por octaedros de $\left[\mathrm{V}^{\mathrm{III}} \mathrm{O}_{2}(\mathrm{OH})_{2} \mathrm{~F}_{2}\right]$ conectados por unidades orgânicas de tereftalatos. Moléculas livres de água estão presentes em pequenas cavidades da estrutura e estão ligadas por pontes de hidrogênio a hidroxilas, o que pode ser comprovado pelos espectros de infravermelho. Os espectros de difração de raios-X mostram que esta MOF é estável até $250{ }^{\circ} \mathrm{C}$, temperatura a partir da qual se inicia um processo que a torna amorfa.
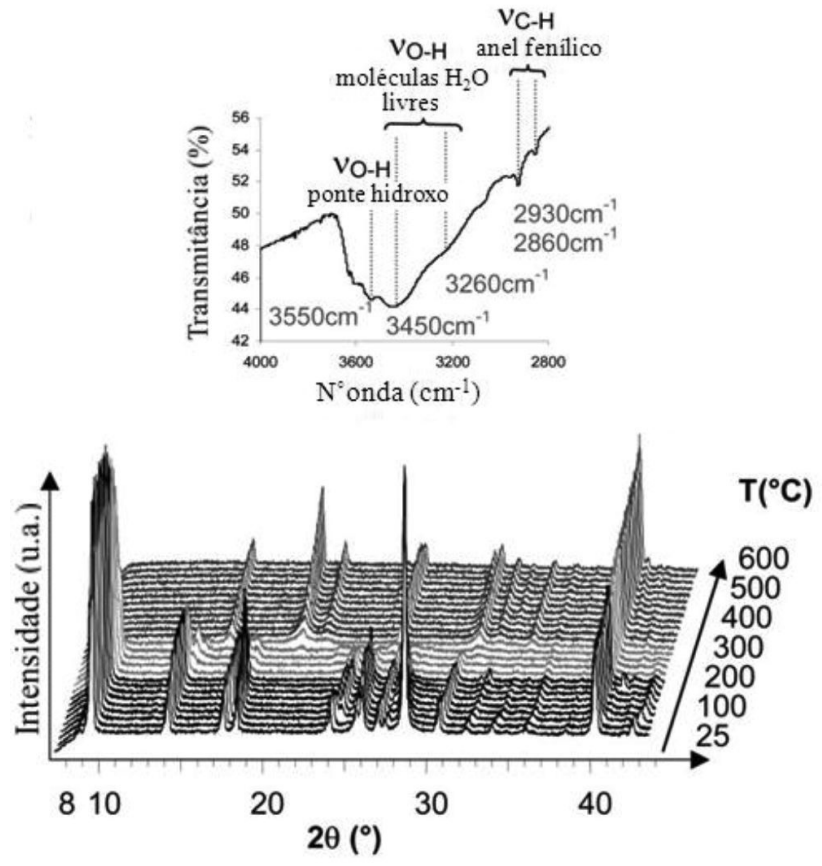

Figura 5. Espectros de absorção no infravermelho e de difração de raios- $X \mathrm{da}$ MOF MIL-71 (ou VIII ${ }_{2}(\mathrm{OH})_{2} \mathrm{~F}_{2}\left\{\mathrm{O}_{2} \mathrm{C}-\mathrm{C}_{6} \mathrm{H}_{4}\right.$ - $\left.\left.\mathrm{CO}_{2}\right\} . \mathrm{H}_{2} \mathrm{O}\right)$ submetida a aquecimento até $600{ }^{\circ} \mathrm{C}$. As bandas de infravermelho em torno de $3500 \mathrm{~cm}^{-1}$ confirmam a presença de grupos $\mathrm{OH}$ e água na estrutura, enquanto as bandas em torno de $2900 \mathrm{~cm}^{-1}$ são características dos anéis fenílicos do ligante. Os espectros de DRX mostram estabilidade até $250{ }^{\circ} \mathrm{C}$. Adaptado da referência $40 \mathrm{com}$ permissão da The Royal Society of Chemistry

A porosidade da MOF pode ser comprovada por técnicas de adsorção, sendo a adsorção de $\mathrm{N}_{2}$ a $77 \mathrm{~K}$, tanto pelo método volumétrico quanto gravimétrico, a mais indicada. Como normalmente as MOFs são microporosas, isotermas do tipo I (classificação IUPAC) são os mais comuns e as equações de Dubinin-Radushkevich, t-plot e Langmuir podem ser aplicadas para determinação das propriedades texturais (área superficial e volume de póros) a partir dos dados do volume adsorvido em função da pressão relativa $\left(\mathrm{p} / \mathrm{p}_{0}\right)$, embora, usualmente, a equação BET seja aplicada. Há estudos com adsorção de outros compostos, tais como $\mathrm{CO}_{2}, \mathrm{H}_{2} \mathrm{O}$ e álcoois.

Quando há interesse nas propriedades de luminescência, torna-se necessário medir o espectro de excitação-emissão em estado sólido da MOF, realizado em espectrofluorômetro, normalmente na faixa de 250 a $550 \mathrm{~nm}$, além da medida do tempo de luminescência, 
também realizada em espectrofluorômetro, em comprimento de onda específico de maior emissão. . $^{27,29,41}$

Dependendo das características das MOFs e aplicações desejadas, outras técnicas de caracterização podem ser empregadas, tais como espectroscopia fotoeletrônica de raios-X (XPS), de absorção de raios-X (XANES), de reflectância difusa (DRS), de absorção no UV-VIS, suscetibilidade magnética, análise elementar, etc.

\section{CARACTERÍSTICAS E APLICAÇÕES DAS MOFS}

Embora as MOFs porosas tenham um desenvolvimento bastante recente, fica clara a série de vantagens desta classe de material. Primeiramente, sua síntese é relativamente simples, na qual se pode modular tanto a estrutura porosa quanto o ambiente químico do sítio ativo, selecionando criteriosamente os blocos de construção (metal e ligante orgânico) e como eles estão conectados.

As zeólitas e compostos similares (aluminofosfatos, silicoaluminofosfatos) não possuem esta flexibilidade, já que a unidade de construção secundária (SBU) são tetraedros de sílica e alumina, com ligações rígidas e bem definidas entre átomos de $\mathrm{Si} / \mathrm{Al}$ com oxigênio, não sendo tão fácil de alterar nem a composição química nem a estrutura, fazendo que suas principais aplicações estejam relacionadas apenas às moléculas visitantes pequenas dentro de sua estrutura. ${ }^{17}$

Quanto às propriedades porosas, com a possibilidade de controle das mesmas, as MOFs podem atuar como peneiras moleculares, selecionando-se as moléculas que podem se difundir nos poros. Dessa forma, as MOFs preenchem uma lacuna entre catalisadores organometálicos superficiais não porosos, zeólitas microporosas e silicatos mesoporosos, com poros que podem variar de ultramicroporos a mesoporos. Em reações em que o controle difusivo não é desejado, pode-se projetar MOFs com poros largos, que se mantêm após ativação.

Em geral, a área superficial pode atingir $6300 \mathrm{~m}^{2} / \mathrm{g}$ e volume de poros de $2 \mathrm{~cm}^{3} / \mathrm{g}$, com poros de dimensões e topologias variadas. A presença de forte interação metal-ligante pode (e deve) conferir porosidade permanente ao material, mesmo após a retirada de moléculas de solvente, sem colapso da estrutura. Esta alta área superficial, facilidade de ajuste do tamanho dos póros e de outras propriedades fizeram com que uma de suas primeiras aplicações reais fosse na área de separação e armazenamento de gases e mostram o potencial para Catálise. Rosi et al. ${ }^{42}$ publicaram um dos primeiros trabalhos de aplicação de MOFs para armazenamento de hidrogênio, no caso a MOF-5, capaz de adsorver 4,5\% do seu peso (17,2 moléculas de hidrogênio por unidade), a $78 \mathrm{~K} \mathrm{e} 1 \%$ à temperatura ambiente e pressão de 20 bar. Com a IRMOF-6 e IRMOF-8, encontrou-se o dobro de consumo (2\%), à temperatura ambiente e 10 bar. Os autores identificaram dois sítios de adsorção, sendo um no átomo de zinco e outro no ligante BDC. Trabalhos posteriores com a MOF-5 obtiveram uma capacidade de armazenamento de $7,1 \%$ a $77 \mathrm{~K}$ e 40 bar, $10 \%$ a 100 bar e uma densidade de estocagem de $66 \mathrm{~g} \mathrm{~L}^{-1}$, próxima do $\mathrm{N}_{2}$ líquido. ${ }^{43}$

Murray et $a l .{ }^{43}$ publicaram uma revisão sobre esta aplicação. Segundo eles, para o desenvolvimento de células a combustível, há necessidade de desenvolver materiais de baixo custo e peso, que possam estocar hidrogênio rápida e reversivelmente, em condições próximas da ambiente, com uma densidade igual ou maior à do hidrogênio líquido. As MOFs, com suas altas áreas superficiais, seriam candidatas naturais para esta aplicação. A adsorção seria por forças de van der Waals, isto é, com baixo calor de adsorção (4-7 kJ mol-1) e fracas. Isto faz com que o principal desafio para esta aplicação seja aumentar esta energia de ligação, de forma que quantidades significativas podem ser adsorvidas à temperatura ambiente. Cargas parciais na estrutura tornariam a ligação mais forte, de caráter dipolo-dipolo. Caso a entalpia de adsorção chegue a $20 \mathrm{~kJ} \mathrm{~mol}^{-1}$, a quantidade fisissorvida poderia aumentar num fator de 3-4. Calores de adsorção maiores que este não seriam desejados, por resultar em grandes liberações de calor no momento da adsorção e dificuldade de dessorção. Três métodos poderiam ser empregados para este aumento: introduzir sítios de coordenação metálicos abertos, promover a interpenetração (criando pequenos poros) e o fenômeno de spillover (migração do hidrogênio do metal para a rede). A quantidade adsorvida também dependeria do tamanho do póro. Os autores citam mais de 150 trabalhos de adsorção de $\mathrm{H}_{2}$ com MOFs e procuraram relacionar a estrutura delas com a performance de armazenamento, através de técnicas de caracterização. Outra revisão interessante sobre o assunto é a publicada por Sculley et al. ${ }^{44}$

Segundo Czaja et al. ${ }^{45}$ embora sejam conhecidas várias características promissoras, apenas um número limitado de aplicações para as MOFs já foram discutidas, sendo que nenhuma delas foi aplicada industrialmente. No entanto, os autores apontam várias aplicações promissoras, dentre elas a purificação, separação e estocagem de gases e catálise heterogênea. $O$ potencial para armazenamento reside na alta área superficial e ausência de volumes mortos. Além do hidrogênio, eles citam o armazenamento de metano e acetileno, que também foram estudados por outros autores. Na purificação de gases, os autores citam a remoção de traços de compostos de enxofre, aminas, fosfinas, oxigenados, álcóois e água que, por serem compostos doadores de elétrons, teriam muita afinidade a sítios de coordenação metálicos disponíveis, com uma capacidade de adsorção (70 $\mathrm{g}$ de tetrahidrotiofeno por $\mathrm{L}$ de MOF) uma ordem de magnitude superior a materiais comerciais à base de carvão ativado. Na separação de gases, eles citam a separação de criptônio do xenônio, de metano do gás natural e de hidrogênio do nitrogênio já realizadas com MOFs, sendo a separação do $\mathrm{CO}_{2}$ de emissões gasosas uma das aplicações mais promissoras, embora atualmente o desempenho seja inferior aos tradicionais lavadores com soluções de amina. A aplicação para adsorção seletiva e separação de gases também foi estudada por Li et al. ${ }^{46}$ Segundo os autores, a capacidade de adsorção depende da pressão de equilíbrio, temperatura, natureza do adsorbato e dos microporos do adsorvente. Já a seletividade para adsorção é significativamente mais complicada de prever, mas dependeria dos mesmos fatores. A flexibilidade da síntese das MOFs, tanto na estrutura porosa quanto química, tornam essas redes promissoras para esta aplicação. Interações específicas molécula visitante-matriz (Ex: pontes de hidrogênio) podem ser geradas com a remoção de moléculas do solvente, fazendo a MOF ter bastante afinidade para adsorção de certos grupos funcionais, tais como álcoois. ${ }^{16}$

Férey et $a l^{47}$ sintetizaram uma MOF à base de cromo e tereftalato, batizada de MIL-101, com célula unitária cúbica, com duas cavidades, uma maior hexagonal e uma menor pentagonal, área BET de $4100 \mathrm{~m}^{2} \mathrm{~g}^{-1}$. Devido às largas janelas, eles visualizaram aplicação deste material para adsorção de gás ou moléculas maiores. Eles provaram isto com a incorporação de poliânions Keggin, com o precursor $\mathrm{K}_{7} \mathrm{PW}_{11} \mathrm{O}_{40} \cdot \mathrm{nH}_{2} \mathrm{O}$ e vislumbraram possibilidade de introdução de espécies e a promoção de reações favorecidas por efeito de confinamento (similar à pressão), com monodispersão de nanomateriais e carreador de princípios ativos de medicamentos, com liberação controlada (drug delivery). Esta última aplicação tem sido estudada por alguns grupos, tomando como princípio a alta área superficial das MOFs e a possibilidade de armazenar moléculas orgânicas um pouco maiores, com seletividade. Horcajada et al. ${ }^{48}$ reportaram uma capacidade de adsorção de até 1,4 gramas de ibuprofen por grama da MOF MIL-101 desidratada, com liberação controlada. ValletRegí et al. ${ }^{49}$ destacam a aplicação em reparo de tecidos ósseos. Um grupo de pesquisa brasileiro, da UFPE, reportou um trabalho com o método de acoplamento molecular para distinguir o desempenho de medicamentos candidatos para incorporação em MOFs. ${ }^{50}$ Outros trabalhos interessantes do mesmo grupo abordam o uso de MOFs à base de lantanídeos com propriedades fotoluminescentes que podem 
ser utilizadas como marcadores óticos para identificação de resíduos de pólvora, em especial em munições sem chumbo. ${ }^{51,52}$

A propósito, este mesmo grupo publicou, até o momento, o único artigo de uma revista nacional indexada, em português, sobre MOFs, na revista Química Nova, abordando a síntese hidrotermal da MOF $\left[\mathrm{Zn}(\mathrm{bdc})\left(\mathrm{H}_{2} \mathrm{O}\right)_{2}\right]_{\mathrm{n}}$ assistida por microondas, ${ }^{53}$ embora se encontrem na literatura alguns artigos sobre polímeros de coordenação, ${ }^{54,55}$ mas sem atender ao critério definido para MOF: manter uma estrutura porosa após remoção de moléculas do solvente. Uma pesquisa no portal do periódico "Brazilian Journal of Chemical Society" mostra apenas 1 trabalho sobre MOF, do prof. Ricardo Longo, da UFPE, um trabalho teórico sobre a análise conformacional de um dipeptídeo protonado dentro das cavidades de MOFs tipo IRMOFs-phen, com ligante 2,7-dicarboxilato fenantreno, com aplicação na catálise enantiomérica. ${ }^{56}$

Quanto à aplicação como sensores químicos, ela pode estar baseada tanto nas propriedades magnéticas quanto óticas. Algumas MOFs têm algumas de suas propriedades magnéticas alteradas (Ex: temperatura crítica de magnetismo, ferrimagnetismo/ferromagnetismo/antiferromagnetismo) quando armazenam/liberam moléculas visitantes devido a transformações estruturais reversíveis, seja devido à mudança de estrutura amorfa para cristalina, seja uma transformação de fases cristalinas. Desta forma, elas podem ser utilizadas como sensores de reconhecimento molecular. As moléculas mais comuns que provocam estas transformações são água e álcoois. ${ }^{57,58}$

Sendo assim, MOFs com estruturas flexíveis têm um interesse tecnológico intrínseco para sensores. Esta sensibilidade está bastante relacionada com a existência de sítios de coordenação metálicos livres. A propriedade de luminescência também está relacionada a isto. Em geral, a luminescência é resultante de decaimento radiativo (isto é, emissão de luz) por moléculas eletronicamente excitadas, após um processo de absorção de energia. Quando esta absorção ocorre de um campo eletromagnético na forma de fótons (luz), a subsequente emissão de luz é chamada de fotoluminescência. ${ }^{59}$

No caso das MOFs, a luminescência pode ocorrer tanto devido a estruturas presentes nos ligantes (Ex: grupos aromáticos) quanto devido a íons lantanídeos com esta habilidade, tais como a $\mathrm{M}_{2}(\mathrm{bdc})_{3}$. $\left(\mathrm{H}_{2} \mathrm{O}\right)_{4}$, sendo $\mathrm{M}=\mathrm{Eu}$ ou $\mathrm{Tb}$, reportada por Reineke et al. ${ }^{41}$ Isto gera potencial de aplicação tanto para sensores químicos como para fotocatálise, mostradores eletroluminescentes, detecção de radiação, efeitos óticos não lineares, etc. ${ }^{27,59}$

$\mathrm{Na}$ aplicação como sensor químico, quando as moléculas do solvente são liberadas, centros metálicos ficam disponíveis para adsorverem moléculas como a própria água, amônia ou outras moléculas que são emissoras ou sensíveis. Quando ocorre esta adsorção, a constante de decaimento de luminescência ou comprimentos de onda do espectro de emissão se alteram, podendo assim se utilizar destas medidas para detectar a presença destas moléculas. Allendorf et al. ${ }^{60}$ descrevem o chamado efeito antena, que consiste na presença de um composto fluoróforo, seja na estrutura da MOF, seja adsorvido no centro metálico, que tem a função de aumentar a intensidade e tempo de luminescência através da transferência de energia absorvida para o metal, o que em geral é necessário nos lantanídeos, que emitem fluorescência com comprimento de onda bem definido, mas que possuem baixo coeficiente de absorção de radiação, principalmente quando há moléculas de água coordenadas.

Quanto à aplicação para troca iônica, trata-se de uma das mais antigas. O trabalho de Hoskin e Robson, em 1990, já previa a capacidade de troca de ânions com polímeros de coordenação porosos. ${ }^{8}$ Aliás, esta é uma diferença em relação às zeólitas, que normalmente trocam cátions, enquanto as MOFs tendem a ter redes catiônicas, construídas com íons metálicos catiônicos e ligantes neutros, tendo preferência para acomodar contra-ânions em sua cavidade, ligado ao metal. Hoje existem vários registros do uso das MOFs para esta aplicação: troca $\mathrm{H} / \mathrm{D}, \mathrm{BF}_{4}-\mathrm{PF}_{6}^{-}, \mathrm{NO}_{2}{ }^{-1} / \mathrm{NO}_{3}{ }^{-}$e hidrogênio. ${ }^{57}$ No entanto, a maior parte das aplicações industriais envolve troca de cátions, para tratamento de água, por exemplo. Trocar o metal dos nós pode significar o colapso da estrutura. Sendo assim, a estratégia para troca catiônica passa por desenvolver MOFs iônicas, com a rede aniônica necessitando de contra-cátions. ${ }^{61,62}$ Por exemplo, com estruturas similares às zeólitas. ${ }^{63}$

\section{MOFS APLICADAS À CATÁLISE}

Alguns bons artigos de revisão da aplicação das MOFs em catálise já foram publicados, ${ }^{1,12,64}$ muitos deles mais focados na catálise assimétrica/enantioseletiva, ${ }^{65-68}$ centenas de reações já foram reportadas, de forma que o objetivo deste artigo é fornecer ao leitor uma visão geral, explicar onde reside esta atividade catalítica e dar um foco um pouco maior na aplicação catalítica de duas classes de MOFs: à base de lantanídeos e de vanádio.

Conforme já discutido anteriormente, algumas características das MOFs, tais como alta área superficial e flexibilidade de síntese e da estrutura, tornam-nas promissoras para aplicações catalíticas. Isto já foi vislumbrado pelos primeiros autores que trabalharam com polímeros de coordenação. ${ }^{10} \mathrm{~A}$ estrutura porosa modulável as tornam candidatas naturais a reações que exigem seletividade de forma, tais como as zeólitas. Quanto ao ambiente químico, é possível modular as interações entre a fase ativa e a molécula visitante (inclusive moléculas adsorvidas) e os estados de transição formados por reações químicas. As MOFs permitem uma alta densidade de sítios catalíticos, em particular quando os sítios ativos são metais de transição.

No entanto, na prática, este uso ainda é bastante restrito, devido a uma combinação de dois fatores: a menor estabilidade em relação à temperatura, umidade e reagentes comparada com materiais similares, como as zeólitas, e o bloqueio de sítios ativos pelo ligante orgânico, não deixando posições livres disponíveis para quimissorção dos reagentes. ${ }^{1}$ Quanto à baixa estabilidade, isto se deve à presença de ligantes orgânicos e à menor força da ligação metal-ligante comparada às ligações covalentes Si-O. Quanto à estabilidade química, ela está bastante relacionada com o metal de coordenação e costuma ser maior em hidrocarbonetos e solventes apolares. A umidade pode afetar a estabilidade estrutural das MOFs. Quanto à estabilidade térmica, ela é limitada à faixa de $300-400{ }^{\circ} \mathrm{C}$ em ar, dependendo do ligante orgânico utilizado. Sendo assim, o desenvolvimento recente de MOFs com aplicações catalíticas passa por minimizar estes problemas.

Corma et al. ${ }^{1}$ dividiram a atuação das MOFs em Catálise em 3 grandes grupos:

a) MOFs com sítios metálicos ativos - estes podem estar isolados ou em grupamentos (clusters), conectados pelos ligantes orgânicos. Além disso, MOF pode ter apenas um tipo de centro metálico, que age simultaneamente como componente de construção estrutural (nó) e como sítio ativo catalítico, ou então com dois tipos de metais, sendo um deles responsável pela atividade catalítica (presente no ligante) e o outro com papel estrutural (presente no nó). Conforme discutido anteriormente, a remoção de moléculas de solvente pode tornar o centro metálico com local de coordenação disponível, o que abre um leque de aplicações em reações que exigem sítios ácidos de Lewis. No entanto, se o metal ativo está no ligante, não agindo como componente estrutural, outras funcionalidades se abrem.

b) MOFs com grupos funcionais reativos - neste caso, os sítios ativos estão nos grupos funcionais do ligante orgânico, que devem estar livres e acessíveis para interagir com o substrato. Um dos mais estudados é o grupamento amina e seus derivados por processos de pós-funcionalização, mas também de grupos piridínicos e carboxilatos. Estes grupos normalmente agem como sítios básicos 
e promovem reações como a condensação de Knoevenagel. No entanto, as MOFs MIL-101 (Cr) e MIL-53 (Al) pós-funcionalizadas com grupamentos sulfoxi por Goesten et al. ${ }^{33}$ mostraram excelente atividade para a esterificação do ácido acético com n-butanol, uma reação que exige sítios ácidos, mostrando um novo campo de aplicação para as MOFs. A maior parte das reações de catálise assimétrica, que serão discutidas mais adiante, também se enquadra nesta categoria. Outra estratégia para promover reações com os grupos funcionais é coordená-lo na vacância metálica após eliminação do solvente, às vezes com auxílio de um grupo de ancoragem, com o grupo funcional ficando apontado para as cavidades da estrutura porosa, processo denominado grafting.

c) MOFs como matrizes hospedeiras (host matrices) ou como cavidades para reações em escala nanométrica (nanometric reaction cavity) - nesse caso, nenhum dos componentes do MOF (metal e ligante) é diretamente envolvido na catálise, mas sim a estrutura porosa da MOF, que fornece o espaço físico onde a catálise acontece, agindo como microrreatores (nanometric reaction cavity) ou servindo como abrigo onde os centros catalíticos estão encapsulados (host matrices). No caso das matrizes hospedeiras, elas podem hospedar nanopartículas metálicas, de óxidos metálicos ou moléculas convidadas ativas. No primeiro caso, a síntese passa pela introdução de complexos organometálicos na estrutura, tais como metalocenos. ${ }^{69}$ Estes, uma vez incorporados, e pelo fato de serem bastante lábeis, podem gerar nanopartículas metálicas de dimensões pequenas (tipicamente $1,4 \mathrm{~nm}$ ), por redução química ou tratamento fotoquímico, de grande aplicabilidade na Catálise, para reações de oxidação e hidrogenação, por exemplo. Neste caso, o papel das MOFs é muito similar aos suportes catalíticos tradicionais, como silica e alumina, mas aproveitando-se de todas as suas funcionalidades. No caso das nanopartículas de óxidos metálicos, é comum a incorporação de grupamentos de sílica, titânia e óxido de zinco, os dois últimos materiais semi-condutores, com habilidade para promover reações fotocatalíticas, com o ligante orgânico podendo exercer um efeito antena similar ao descrito para a aplicação de luminescência. Sistemas polinucleares também costumam agir como fotocatalisadores. ${ }^{12}$

Por fim, moléculas visitantes cataliticamente ativas também podem ser hospedadas, sendo as metaloporfirinas uma das mais utilizadas, ${ }^{70}$ dada a sua atividade para oxidação de alcanos, epoxidação e ciclopropanação de alcenos. Como moléculas grandes são incorporadas dentro de cavidades, estas sínteses são chamadas de ship-in-a-bottle. Neste caso, ocorre uma espécie de transformação de um catalisador homogêneo em um heterogêneo e um aumento da estabilidade da molécula visitante. A incorporação de heteropoliânions, tais como os polioxometalatos, que podem exibir acidez de Brönsted elevada, promovendo reações como hidratação de alcenos, esterificação, alquilação e oxidação seletiva, também tem sido estudada, superando as desvantagens deste material de possuir baixa área superficial e ter tendência à aglomeração. ${ }^{71}$

Um grande potencial das MOFs é o desenvolvimento de materiais com grupamentos polinucleares, que se assemelham muito às enzimas, que aliam esta característica a um ambiente químico e estrutural específico. Os MOFs têm potencial para preencher a lacuna entre as zeólitas e as enzimas se tiverem três características: sítios polinucleares isolados, interação específica sítio ativo-substrato e um ambiente da cavidade com hidrofobicidade ajustável. Dada a similaridade com as enzimas, este material é denominado biomimético. O reconhecimento molecular é característico das enzimas, com uma resposta substrato-sítio ativo específica. Ele não é possível nas zeólitas, dada a rigidez da sua estrutura, mas é perfeitamente possível nas MOFs, dada a flexibilidade de sua síntese e ao fato da sua estrutura ser flexível (MOFs de terceira geração). Quanto à hidrofobicidade, ela pode ser controlada nas MOFs, tanto pela escolha do ligante quanto por modificações pós-síntese, o que pode aumentar a eficiência catalítica para determinada reação. ${ }^{12}$

De uma forma geral, a baixa estabilidade térmica limita o uso das MOFs em reações em fase gás, em temperaturas acima de $300^{\circ} \mathrm{C}$, tais como refino e processos petroquímicos, principalmente se as reações geram coque e produtos mais pesados. ${ }^{1}$ Nesses casos, as zeólitas continuarão a ser utilizadas, mas, em reações a baixas temperaturas, tais como a isomerização de alcanos, é esperado que as MOFs desativem muito menos, além de ser possível sintetizar facilmente MOFs com sítios metálicos/ácidos bifuncionais. Também se vislumbra um grande potencial de uso das MOFs em reações de síntese orgânica em fase líquida, aplicadas principalmente na química fina.

A literatura mostra a aplicação das MOFs em diversas reações químicas. As MOFs têm flexibilidade para atuar como catalisador ácido de Lewis, ácido de Bronsted (Ex: acilação Friedel-Crafts), base de Lewis, reações de oxidação e polimerização/formação de ligação C-C (Ex: acoplamento Suzuki-Miyaura). Como testes catalíticos para avaliar seus sítios ácidos de Lewis, a reação de cianosililação de aldeídos, representada na Figura 6, é comumente empregada. ${ }^{72}$ Já para sítios básicos, a reação de condensação de Knoevenagel é bastante estudada. ${ }^{73}$ A condensação Aldol, representada na Figura 7, é uma outra reação bastante empregada para avaliar os sítios ácidos e básicos de Lewis. ${ }^{74,75}$ Há ainda registro de diversas reações nas quais os MOFs possuem atividade catalítica, tais como: hidrogenação, redução de nitrobenzeno, isomerização, acetalização, hidrodessulfurização, (trans)esterificação, etc. ${ }^{1}$

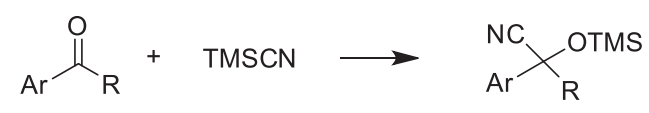

Figura 6. Reação de cianosililação de aldeídos $(R=H)$ ou cetonas ( $R=$ grupo alquílico), utilizada para caracterizar os sítios ácidos das MOFs

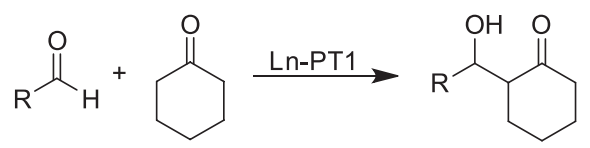

Figura 7. Reação de condensação Aldol da cicloexanona com aldeídos, utilizada para caracterizar os sítios básicos das MOFs

Vale destacar uma classe de reações onde as MOFs têm sido aplicadas: a catálise assimétrica (enantiomérica), resultante da flexibilidade da sua estrutura das MOFs. O confinamento de substratos quirais ou configurações particulares de complexos organometálicos nos microporos, inclusive com possibilidade de rotação como resultado de estímulo externo ou molécula visitante, pode induzir ou promover a enantioseletividade, de grande valor na indústria de fármacos. Estas MOFs são sintetizadas com base na escolha criteriosa de blocos de construção quirais, por meio do uso de direcionadores de estrutura (templates) ou de modificações pós-síntese e troca de molécula visitante. ${ }^{66} \mathrm{O}$ mesmo princípio serve para explicar a aplicação destas MOFs homoquirálicas para separação de enantiômeros.

\section{CATÁLISE COM MOFS À BASE DE VANÁDIO}

O vanádio é um metal de transição do grupo 5B. O óxido de vanádio e seus derivados (Ex: fosfatos - VPO, aluminofosfatos e acetilacetonatos) têm sido utilizado na Catálise em uma série de aplicações, principalmente em oxidações seletivas, tanto com complexos homogêneos à base de vanádio ou com estes imobilizados em matrizes micro ou mesoporosas como sílica e zeólitas, na forma heterogênea. ${ }^{76}$ Por exemplo, a oxidação parcial do n-butano a anidrido maleico 
utilizando óxido misto de vanádio e fósforo é um processo comercial, sendo as ligações $\mathrm{V}$-O-suporte funcionalidades cinéticas críticas para esta reação. ${ }^{77} \mathrm{~A}$ epoxidação de olefinas, de interesse para produção de epóxidos como os óxidos de acetileno e propileno, intermediários químicos na síntese de produtos naturais, substâncias biologicamente ativas, glicóis e resinas, também têm sido estudadas. Outra reação aplicada é a amoxidação de olefinas ou compostos aromáticos. ${ }^{78} \mathrm{~A}$ atividade e seletividade das espécies de vanádio nestas reações está bastante relacionada com os estados de oxidação que o vanádio pode assumir $(\mathrm{de}+2 \mathrm{a}+5)$, se ele está isolado (monomérico) ou na forma de espécies polimerizadas, ao ambiente de coordenação (tetraédrico, pentaédrico, octaédrico), dispersão e estabilidade das espécies. ${ }^{79} \mathrm{O}$ estado $\mathrm{V}^{5+}$ tende a formar polioxoânions e espécies superficiais com este número de oxidação, em baixos teores de vanádio, costuma formar espécies monoméricas $\mathrm{VO}_{4}$ com boa atividade catalítica para reações como a desidrogenação oxidativa de alcanos. ${ }^{80}$ No caso dos VPOs, a presença das espécies pirofosfato de vanadila, (VO) ${ }_{2} \mathrm{P}_{2} \mathrm{O}_{7}$, com $\mathrm{V}^{4+}$, e da espécie $\mathrm{VOPO}_{4}, \mathrm{com} \mathrm{V}^{5+}$, tem sido identificada como crítica para o desempenho industrial. ${ }^{81,82}$

No entanto, aplicações catalíticas das MOFs à base de vanádio não são tão reportadas na literatura quanto as de lantanídeos, por exemplo. Dado o histórico do estudo de imobilização de complexos de vanádio em matrizes micro e mesoporosas, torna-se evidente que as MOFs, com suas vantagens, tem um potencial para as mesmas aplicações. Um dos primeiros trabalhos sobre MOFs à base de vanádio foi o de Barthelet et $a l .{ }^{83}$ que reportam a síntese da MOF MIL-47(V), ou VIV $\mathrm{O}\left\{\mathrm{O}_{2} \mathrm{C}-\mathrm{C}_{6} \mathrm{H}_{4}-\right.$ $\mathrm{CO}_{2}$ \}, com estrutura 3-D ortorrômbica, utilizando $\mathrm{VCl}_{3}$ como precursor de vanádio e ácido tereftálico como ligante. Os autores reportaram uma área superficial BET de $930 \mathrm{~m}^{2} \mathrm{~g}^{-1}$. Em trabalho posterior ${ }^{84}$ o grupo mostrou que certo grau de flexibilidade pode ser introduzido nesta estrutura controlando o estado de oxidação do vanádio, o que seria importante para as aplicações de separação e estocagem seletiva de gases. Outro trabalho de $\mathrm{MOF}$ à base de vanádio que merece destaque é o de Lieb et al. ${ }^{85}$ sobre a $\mathrm{MOF} \mathrm{V}_{3} \mathrm{O}\left(\mathrm{H}_{2} \mathrm{O}\right)_{2} \mathrm{X}\left[\mathrm{C}_{9} \mathrm{H}_{3} \mathrm{O}_{6}\right]_{2} \cdot \mathrm{yH}_{2} \mathrm{O}$, sendo $\mathrm{x}=\left(\mathrm{Cl}^{-}\right)_{1-\mathrm{z}}\left(\mathrm{C}_{9} \mathrm{H}_{5} \mathrm{O}_{6}\right)_{7}^{-}$, batizada de MIL-100(V), com arquitetura similar às zeólitas, cavidades mesoporosas de 5 e $29 \AA$, acessíveis através de janelas de 5,5 e 8,9 ̊̊ e área BET de $2320 \mathrm{~m}^{2} \mathrm{~g}^{-1}$.

Leusa et al. ${ }^{86}$ utilizaram esta mesma MIL-47(V) na reação de oxidação do cicloexeno com hidroperóxido de terc-butila, comparando seu desempenho com catalisadores referências de vanádio (VAPO-5, $\mathrm{VO}_{x} / \mathrm{SiO}_{2}$ e o catalisador homogêneo $\left.\mathrm{VO}(\mathrm{acac})_{2}\right)$. A MOF mostrou um desempenho catalítico superior, preservando sua estrutura cristalina e área superficial após a reação e desativando pouco.

Outra reação com emprego de MOFs à base de vanádio é a do metano com peroxidissulfato de potássio, produzindo ácido acético, estudada por Phan et al..$^{87} \mathrm{com}$ as MOFs MIL-47 e MOF-48. Eles obtiveram um rendimento de $70 \%$ e os catalisadores puderam ser reutilizadas diversas vezes, permanecendo cataliticamente ativos e com sua estrutura cristalina intacta.

Liu et. al.$^{88}$ desenvolveram uma nova MOF não porosa, batizada de COMOC-3as, com a fórmula estrutural $\mathrm{V}^{\mathrm{III}}(\mathrm{OH})\left(\mathrm{O}_{2} \mathrm{C}-\mathrm{C}_{10} \mathrm{H}_{6}-\right.$ $\left.\mathrm{CO}_{2}\right) \cdot \mathrm{H}_{2} \mathrm{O}$, sintetizada a partir do precursor $\mathrm{VCl}_{3}$ e do ligante NDC (ácido 2,6-naftalenodicarboxílico). A caracterização mostrou uma estrutura similar à MOF MIL-69 e o $\mathrm{V}^{3+}$ pode ser oxidado $\mathrm{a} \mathrm{V}^{4+}$ mantendo a topologia da rede. A MOF foi testada na reação de oxidação do cicloexeno em fase líquida, com conversão de $38 \%$ em 7 horas e seletividade de $82 \%$ para cicloexeno, comparável à MOF MIL-47 e com lixiviação de vanádio negligível, possibilidade de regeneração e manutenção da performance catalítica.

\section{CATÁLISE COM MOFS À BASE DE LANTANÍDEOS}

As MOFs à base de íons lantanídeos tem atraído bastante interesse na última década devido às suas propriedades magnéticas e de luminescência. ${ }^{20}$ Por isto, existem inúmeros trabalhos publicados com estes materiais, conhecendo-se vários aspectos relacionados à sua síntese e caracterização, o que torna natural se vislumbrar aplicações em outras áreas, tais como Catálise.

Em termos de coordenação, os íons lantanídeos têm uma esfera flexível, tornando possível criar MOFs com centros metálicos coordenativamente insaturados com a eliminação de moléculas visitantes (Ex: aquecimento), formando canais 1D de alta estabilidade térmica (350-500 ${ }^{\circ} \mathrm{C}$ ) e gerando sítios ácidos e básicos de Lewis, tornando-as potenciais catalisadores para reações que necessitem destes sítios. ${ }^{89}$

Um dos primeiros estudos com a aplicação de polímeros de coordenação à base de lantanídeos como catalisadores foi o de Reineke et al.,$^{90}$ que sintetizou a $\mathrm{MOF}\left[\mathrm{Tb}(\mathrm{bdc})\left(\mathrm{NO}_{3}\right)\right] .2 \mathrm{dmf}$, cuja forma dessolvatada apresentou uma estrutura microporosa que manteve sua topologia após dessolvatação e se mostrou estável até $450{ }^{\circ} \mathrm{C}$. Em seguida, Dewa et al.,$^{91}$ estudaram um material sintetizado com o composto $\mathrm{La}\left(\mathrm{O}^{\mathrm{i}} \mathrm{Pr}\right)_{3}$ e o composto orgânico antracenobisresorcinol, na época nem mesmo batizado como MOF e sem dados de cristalinidade, mas que apresentou uma área BET de $230 \mathrm{~m}^{2} \mathrm{~g}^{-1}$. Este composto foi ativo na reação de troca hidrogênio/deutério, o que, pelos mecanismos de reação, mostra potencial de aplicação nas reações de enolização de cetonas e condensação Aldol, reações tipicamente catalisadas por ácidos e bases de Lewis. Outros autores utilizaram estas reações para avaliar as suas MOFs à base de lantanídeos. Wu et al. ${ }^{92}$ estudando MOFs do tipo $\left[\mathrm{Tb}_{6}\left(\mathrm{H}_{3} \mathrm{~L}\right)_{4}\left(\mathrm{NO}_{3}\right)_{9}-3 \mathrm{H}^{+}\right]^{6+}$, onde $\mathrm{H}_{3} \mathrm{~L}$ era um ligante com grupo piridina, verificaram que a presença de cicloexanona leva à mudanças no espectro de absorção da MOF e aumento de luminescência. Desta forma, eles concluíram que as interações entre a cicloexanona e os grupos amida das MOFs foram dominantes para ativar a cicloexanona na reação de condensação Aldol, que possivelmente ocorreria nas cavidades do octaedro. Sen $e t$ al. ${ }^{93}$ trabalhando com MOFs de neodímio e praseodímio, utilizando ligantes carboxilados, com estrutura de prisma trigonal, mostraram que estas MOFs eram muito mais ativas e seletivas na epoxidação de várias olefinas, cíclicas e alifáticas, que seus respectivos óxidos.

A reação de cianosililação de aldeídos e cetonas, uma espécie de incorporação dos grupos $\mathrm{CN}$ e $\mathrm{SiMe}_{3}$ ao átomo de carbono, representada na Figura 6, também pode ser utilizada como reação modelo para avaliar os sítios ácidos de Lewis das MOFs à base de lantanídeos..$^{89,90,94,95} \mathrm{Wu}$ et al.${ }^{92}$ concluíram que as interações correspondentes ao sítios de $\mathrm{Tb}^{3+}$ foram dominantes para a ativação dos aldeídos. D'Vries et al..$^{96}$ também estudaram esta reação e concluíram que acidez destes materiais está diretamente ligada ao raio iônico do lantanídeo, variando de forma inversa. Em outro trabalho do grupo, ${ }^{97}$ trabalhando com MOFs com o ligante 3,5-benzenodissulfonato, eles concluíram que a atividade catalítica depende principalmente da estrutura da rede, com pouca influência do cátion de lantanídeo utilizado e que o mecanismo inclui, provavelmente, uma troca de moléculas de água coordenadas ao metal por aldeído antes da ativação do catalisador.

Em relação aos sítios básicos de Lewis, a reação de condensação de Knoevenagel com aldeídos é bastante utilizada para avaliação, pois requer a formação de um ânion de um composto básico ativo que contém metileno. Wu et al. ${ }^{94}$ desenvolveram uma MOF à base de térbio que continha tanto sítios ácidos quanto básicos de Lewis, sendo os ácidos presentes no $\mathrm{Tb}^{3+}$ e os básicos nos sítios de trifenilamina dos ligantes, apresentando atividade tanto para a cianosililação quanto para a reação Knoevenagel.

Existem outras reações já citadas na literatura das MOFs à base de lantanídeos, tais como a acetalização do benzaldeído com metanol, utilizada por Ren et al..$^{98}$ para avaliar a atividade dos sítios ácidos de Lewis de MOFs de lantanídeos com o ligante 1,4-fenilenodiacetato. Gandara et al. ${ }^{99}$ mostraram que MOFs de vários lantanídeos com o 
ligante naftalenodissulfonato foram ativas para a oxidação de linalool com peróxido de hidrogênio, produzindo compostos (óxidos, éteres) utilizados na indústria de perfumes, reação que necessita de catalisadores bifuncionais com sítios ácidos e redox. O mesmo grupo mostrou a atividade de MOFs de itérbio para a mesma reação e também para a hidrodessulfurização do tiofeno e oxidação de sulfetos, mostrando a importância da densidade de carga e do número de coordenação no átomo do lantanídeo para o desempenho catalítico ${ }^{100} \mathrm{Em}$ outro trabalho, com MOFs de $\mathrm{Yb}$ e ácido succínico, eles propuseram um mecanismo para a oxidação de sulfetos, baseado em evidências espectroscópicas, em que as espécies $\mathrm{Yb}-\mathrm{O}-\mathrm{OH}$ seriam responsáveis pela atividade catalítica. ${ }^{101}$ Eles também testaram as mesmas MOFs para as reações de oxidação de metilsulfanilbenzeno e acetalização de benzaldeído. MOFs de lantanídeos também foram testadas por Cunha-Silva et al. ${ }^{102}$ na reação de ciclodesidratação de xilose a fulfural e por Vitorino et al. ${ }^{103}$ na polimerização de Ziegler-Natta.

\section{CONCLUSÕES}

As redes metalorgânicas (MOFs), polímeros de coordenação porosos e cristalinos, têm um desenvolvimento que pode ser considerado ainda na infância. A flexibilidade envolvida na sua síntese, a depender da escolha do precursor metálico e do ligante orgânico, podendo gerar estruturas flexíveis, a depender da molécula visitante e como resposta a estímulos externos (calor, luz, campo magnético) e a sua grande porosidade as tornam potenciais candidatas para uma série de aplicações, tais como sensores químicos baseados em suas propriedades óticas, magnéticas e elétricas, separação seletiva, purificação e armazenamento de gases, troca iônica, detector de radiação, mostradores eletroluminescentes, etc. Na Catálise, os sítios ativos podem estar localizados tanto no ligante orgânico quanto no centro metálico, ou ainda a MOF pode ser aplicada como matriz hospedeira de materiais cataliticamente ativos, tais como nanopartículas metálicas. Isto as torna potenciais catalisadores para diversas reações, nas quais, na maior parte delas, a atividade está relacionada com a remoção de moléculas de solvente coordenadas ao metal, gerando vacâncias de coordenação que podem ser ocupadas por reagentes, atuando como sítios ácidos ou básicos de Lewis. Dentre algumas reações nas quais as MOFs já são aplicadas, destacam-se a fotocatálise, catálise assimétrica, epoxidação de olefinas, cianosililação de aldeídos, condensação de Knoevenagel, condensação Aldol, hidrodessulfurização, acetalização de benzaldeído, oxidações, etc.

Até o momento, apenas as aplicações mais fáceis e diretas foram estudadas e o desenvolvimento destes materiais tende a aproximá-los do comportamento catalítico observado em enzimas, com os ligantes sendo formados por complexos de metais de transição, combinando a presença de sítios uni ou multimetálicos com o confinamento molecular nos poros. Há também um grande potencial para reações de conversão de biomassa, que envolve moléculas grandes, tais como triglicerídeos, terpenos e carboidratos. Espera-se que, assim como ocorreu com as zeólitas, a gradual introdução das MOFs como catalisador industrial dê relevância à área e estimule novas pesquisas, sem necessariamente substituir as zeólitas e zeotypes, mas sejam complementares em reações específicas, como a produção de produtos químicos e da química fina.

\section{REFERÊNCIAS}

1. Corma, A.; Garcia, H.; Xamena, F. X. L.; Chem. Rev. 2010, 110, 4606.

2. Rowsell, J. L. C.; Yaghi, O. M.; Microporous Mesoporous Mater. 2004, 73,3 .

3. Wee, L. H.; Alaerts, L.; Martens, J. A.; Vos, D. D.; Em Metal-Organic Frameworks: Applications from Catalysis to Gas Storage; Farruseng, D., ed.; Wiley-VCH: Weinheim, 2011, cap. 9.
4. Wells, A. F.; Acta Crystallogr. 1954, 7(8-9), 535; Wells, A. F.; Acta Crystallogr. 1954, 7(8-9), 545.

5. Perry IV, J. J.; Perman, J. A.; Zaworotko, M. J.; Chem. Soc. Rev. 2009, $38,1400$.

6. Kinoshita, Y.; Matsubara, I.; Higuchi, T.; Saito, Y.; Bull. Chem. Soc. Jpn. 1959, 32, 1221.

7. Hoskins, B. F.; Robson, R.; J. Am. Chem. Soc. 1989, 111, 5962.

8. Hoskins, B. F.; Robson, R.; J. Am. Chem. Soc. 1990, 112, 1546.

9. Park, K. M.; Iwamoto, T.; J. Chem. Soc., Chem. Commun. 1992, 72; Abrahams, B. F.; Hoskins, B. F.; Robson, R.; J. Am. Chem. Soc. 1991, 113, 3606 .

10. Fujita, M.; Kwon, Y, J.; Washizu, S.; Ogura, K.; J. Am. Chem. Soc. 1994, $116,1151$.

11. Yaghi, O. M.; Li, H.; J. Am. Chem. Soc. 1995, 117, 10401.

12. Farrusseng, D.; Aguado, S.; Pinel, C.; Angew. Chem. Int. Ed. 2009, 48, 7502.

13. Li, H.; Eddaoudi, M.; O'Keeffe, M.; Yaghi, O. M.; Nature 1999, 402, 276.

14. Furukawa, H.; Ko, N.; Go, Y. B.; Aratani, N.; Choi, S. B.; Choi, E.; Yazaydin, A. O.; Snurr, R. Q.; O’Keeffe, M.; Kim, J.; Yaghi, O. M.; Science 2010, 329, 424.

15. Zhao, D.; Timmons, D. J.; Yuan, D.; Zhou, H-C.; Acc. Chem. Res. 2011, 44, 123.

16. Eddaoudi, M.; Moler, D. B.; Li, H.; Chen, B.; Reineke, T. M.; O'Keefee, M.; Yagui, O. M.; Acc. Chem. Res. 2001, 34, 319.

17. Brant, J. A.; Liu, Y.; Sava, D. F.; Beauchamp, D.; Eddaoudi, M.; J. Mol. Struct. 2006, 796, 160.

18. Vagin, S. I.; Ott, A. K.; Rieger, B.; Chem. Ing. Tech. 2007, 79, 767.

19. Tranchemontagne, D. J.; Mendoza-Cortés, J.L.; O'Keeffe, M.; Chem. Soc. Rev. 2009, 38, 1257.

20. Paz, F. A. A.; Klinowski, J.; Vilela, S. M. F.; Tomé, J. P. C.; Cavaleiro, J. A. S.; Rocha, J.; Chem. Soc. Rev. 2012, 41, 1088.

21. O'Keeffe, M.; Peskov, M. A.; Ramsden, S.; Yaghi, O. M.; Acc. Chem. Res. 2008, 41, 1782.

22. Baten, S. R.; Champness, N. R.; Chen, X. M.; Garcia-Martinez, J.; Kitagawa, S.; Öhrström, L.; O'Keeffe, M.; Suh, M. P.; Reedijk, J.; CrystEngComm 2012, 14, 3001.

23. Kitagawa, S.; Mitsuru, K.; Bull. Chem. Soc. Jpn. 1998, 71, 1739.

24. htttp://www.iupac.org/web/ins/2009-012-2-200, acessada em Maio 2013.

25. Steed, J. W.; Atwood, J. L.; Supramolecular Chemistry, 2nd ed., Wiley: Chichester, 2009.

26. Makiura, R.; Kitagawa, H.; Eur. J. Inorg. Chem. 2010, 3715.

27. Lu, Y.; Lan, Y.; Xu, Y.; Su, Z.; Li, S.; Zang, H.; Xu, G.; J. Sol. St. Chem. 2009, 182, 3105 .

28. Burnett, B. J.; Choe, W.; Dalton Trans. 2012, 41, 3889.

29. Tanase, S.; Mittelmeijeer-Hazeleger, M. C.; Rothenberg, G.; Mathonière, C.; Jubera, V.; Smits, J. M. M.; de Gelder, R.; J. Mater. Chem. 2011, 21, 15544.

30. Tanabe, K. K.; Cohen, S. M.; Chem. Soc. Rev. 2011, 40, 498.

31. Wang, Z.; Cohen, S. M.; J. Am. Chem. Soc. 2007, 129, 12368.

32. Wang, Z.; Cohen, S. M.; Chem. Soc. Rev. 2009, 38, 1315.

33. Goesten, M. G.'; Juan-Alcañiz, .; Ramos-Fernandez, E. V.; Gupta, K. B. S. S.; Stavitski, E.; van Bekkun, H.; Gascon, J.; Kapteijn, F.; J. Catal. 2011, 281, 177.

34. Goto, Y.; Sato, H.; Shinkai, S.; Sada, K.; J. Am. Chem. Soc. 2008, 130, 14354.

35. Mu, B.; Li, F.; Huang, Y.; Walton, K. S.; J. Mater. Chem. 2012, 22, 10172.

36. Xuan-Dong, D.; Vinh-Thang, H.; Kaliaguine, S.; Microporous Mesoporous Mater. 2011, 141, 135.

37. Yang, L.; Song, S.; Zhang, H.; Zhang, W.; Wu, L.; Bu, Z.; Ren, T.; Synth. Met. 2012, 162, 261.

38. Sutrisno, A.; Huang, Y.; Solid State Nucl. Magn. Reson. 2013, 49-50, 1. 
39. Liu, Z.; Fujita, N.; Miyasaka, K.; Han, L.; Stevens, S. M.; Suga, M.; Asahina, S.; Slater, B.; Xiao, C.; Sakamoto, Y.; Anderson, M. W.; Ryoo, R.; Terasaki, O.; Microscopy 2013, 62, 109.

40. Barthelet, K.; Adil, K.; Millange, F.; Serre, C.; Riou, D.; Férey, G.; J. Mater. Chem. 2003, 13, 2208.

41. Reineke, T. M.; Eddaoudi, M.; Fehr, M.; Kelley, D.; Yaghi, O.M.; J. Am. Chem. Soc. 1999, 121, 1651.

42. Rosi, N. L.; Eckert, J.; Eddaoudi, M.; Vodak, D. T.; Kim, J.; O'Keeffee, M.; Yaghi, O. M.; Science 2003, 300, 1127.

43. Murray, L. J.; Dinca, M.; Long, J. R.; Chem. Soc. Rev. 2009, 38, 1294.

44. Sculley, J.; Yuan, D.; Zhou, H.; Energy Environ. Sci. 2011, 4, 2721.

45. Czaja, A. U.; Trukhan, N.; Müller, U.; Chem. Soc. Rev. 2009, 38, 1284.

46. Li, J.; Kuppler, R. J.; Zhou, H.; Chem. Soc. Rev. 2009, 38, 1477.

47. Férey, G.; Mellot-Draznieks, C.; Serre, C.; Millange, F.; Dutour, J.; Surblé, S.; Margiolaki, I.; Science 2005, 309, 2040.

48. Horcajada, P.; Serre, C.; Vallet-Régí, M.; Sebban, M.; Taulelle, F.; Férey, G.; Angew. Chem. Int. Ed. 2006, 45, 5974.

49. Vallet-Régí, M.; Balas, F.; Arcos, D.; Angew. Chem. Int. Ed. 2007, 46, 7548.

50. Rodrigues, M. O.; Paula, M. V.; Wanderley, K. A.; Vasconcelos, I. B.; Júnior, S. A.; Soares, T. A.; Int. J. Quantum Chem. 2012, 112, 3346.

51. Weber, I. T.; Melo, A. J. G.; Lucena, M. A. M.; Rodrigues, M. O.; Júnior, S. A.; Anal. Chem. 2011, 83, 4720.

52. Weber, I. T.; Terra, I. A. A.; Melo, A. J. G.; Lucena, M. A. M.; Wanderley, K. A.; Paiva-Santos, C. O.; Antônio, S. G.; Nunes, L. A. O.; Paz, F. A. A.; Sá, G. F.; A; Júnior, S. A.; Rodrigues, M. O.; RSC Adv. 2012, 2, 3083.

53. Wanderley, K. A.; Júnior, S. A.; Paiva-Santos, C. O.; Quim. Nova, 2011, 34, 434.

54. Santos, R. S.; Jannuzzi, S. A. V.; Formiga, A. L. B.; Quim. Nova, 2010 33, 1815.

55. Cunha, T. T.; Stumpf, H. O.; Pereira, C. L. M.; Pires, H. S.; Oliveira, L. F. C.; Pedroso, E. F.; Nunes, W. C.; Quim. Nova, 2012, 35, 1776.

56. Braga, C. F.; Longo, R. L.; J. Braz. Chem. Soc. 2008, 19, 321.

57. Kitagawa, S.; Kitaura, R.; Noro, S.; Angew. Chem. Int. Ed. 2004, 43, 2334.

58. Ma, L.; Lin, W.; Em Functional Metal-Organic Frameworks: Gas Storage, Separation and Catalysis; Schröder, M., ed.; Springer: Berlin, 2010, 175-205.

59. Perry IV, J. J.; Bauer, C. A..; Allendorf, M. D.; Em Metal-Organic Frameworks: Applications from Catalysis to Gas Storage; Farruseng, D., ed.; Wiley-VCH: Weinheim, 2011, cap. 12.

60. Allendorf, M. D.; Bauer, C. A.; Bhakta, R. K.; Houk, R. J. T.; Chem. Soc. Rev. 2009, 38, 1330.

61. Xiong, S.; Li, S.; Wang, S.; Wang, Z.; CrystEngComm 2011, 13, 7236.

62. Banerjee, D.; Kim, S. J.; Wu, H.; Xu, W.; Borkowski, L. A.; Li, J.; Parise, J. B.; Inorg. Chem. 2011, 50, 208.

63. Nalaparaju, A.; Jiang, J.; J. Phys. Chem. C 2012, 116, 6925.

64. Isaeva, V. I.; Kustov, L. M.; Pet. Chem. 2010, 50, 167.

65. Ma, L.; Abney, C.; Lin, W.; Chem. Soc. Rev. 2009, 38, 1248.

66. Liu, Y.; Xuan, W.; Cui, Y.; Adv. Mater. 2010, 22, 4112.

67. Lin, W.; Top. Catal. 2010, 53, 869.

68. Wang, C.; Zheng, M.; Lin, W.; J. Phys. Chem. Lett. 2011, $2,1701$.

69. Kim, H.; Chun, H.; Kim, G.; Lee, H.; Kim, K.; Chem. Commun. 2006, 26, 2759.

70. Alkordi, M. H.; Liu, Y.; Larsen, R. W.; Eubank, J. F.; Eddaoudi, M.; J. Am. Chem. Soc. 2008, 130, 12639.

71. Maksimchuk, N. V.; Timofeeva, M. N.; Melgunov, M. S.; Shmakov, A. N.; Chesalov, Y. U.; Dybtsev, D. N.; Fedin, V. P.; Kholdeeva, O. A.; J. Catal. 2008, 257, 315

72. Schlichte, K.; Kratzke, T.; Kaskel, S.; Microporous Mesoporous Mater. 2004, 73, 81 .
73. Gascon, J. Aktay, U.; Alonso, M. D. H.; Van Klink, G. P. M.; Kapteijn, F.; J. Catal. 2009, 261, 75.

74. Vermoortele, F.; Ameloot, R.; Vimont, A.; Serre, C.; Vos, D. D.; Chem. Commun. 2011, 47, 1521.

75. Pathan, N. B.; Rahatgaonkar, A. M.; Chorghade, M. S.; Catal. Commun. 2011, 12, 1170

76. Tsoncheva, T.; Ivanova, L.; Dimitrova, R.; Rosenholm, J.; J. Colloid Interface Sci. 2008, 342, 321.

77. Guliants, V. V.; Benziger, J. B.; Sundaresan, S.; Wachs, E.; Stud. Surf. Sci. Catal. 2000, 130, 1721

78. Mikolajska, E.;Garcia, E. R.; Medina, R. L.; Lewandowska, A. E.; Ferro, J. L. G.; Bañares, M.A.; Appl. Catal., A 2011, 404, 93.

79. Bhunia, S.; Koer, S.; J. Porous Mater. 2011, 18, 399.

80. Strassberger, Z.; Ramos-Fernandez, E. V.; Boonstra, A.; Jorna, R.; Tanase, S.; Rothenberg, G.; Dalton Trans. 2013, 42, 5546.

81. Guliants, V. V.; Benziger, J. B.; Sundaresan, S.; Wachs, I. E.; Jehng, J. -M.; Roberts, J. E.; Catal. Today 1996, 28, 275.

82. Mikolajska, E.; Calvino-Casilda, V.; Bañares, M.A.; Appl. Catal., A 2012, 421, 164.

83. Barthelet, K.; Marrot, J.; ;Riou, D.; Férey, G.; Angew. Chem. Int. Ed. 2002, 41, 281.

84. Leclerc, H.; Devic, T.; Devautour-Vinot, S.; Bazin, P.; Audebrand, N.; Férey, G.; Daturi, M.; Vimont, A.; Clet, G.; J. Phys. Chem. C 2011, 115, 19828

85. Lieb, A.; Leclerc, H.; Devic, T.; Serre, C.; Margiolaki, I.; Mahjoubi, F.; Lee, J. S.; Vimont, A.; Daturi, M.; Chang, J. S.; Microporous Mesoporous Mater. 2012, 157, 18.

86. Leusa, K.; Muylaerta, I.; Speybroeckb, V. V.; Marinc, G. B.; van der Voorta, P.; Stud. Surf. Sci. Catal. 2010, 175, 329.

87. Phan, A.; Czaja, A. U.; Gándara, F.; Knobler, C. B.; Yaghi, O. M.; Inorg. Chem. 2011, 50, 7388.

88. Liu, Y. Y.; Leus, K.; Grzywa, M.; Weinberger, D.; Strubbe, K.; Vrielinck, H.; Deun, R. V.; Volkmer, D.; Speybroeck, V.; Voort, P. V. D.; Eur. J. Inorg. Chem. 2012, 16, 2819.

89. Gustafsson, M.; Bartoszewicz, A.; Martin-Matute, B.; Sun, J.; Grins, J.; Zhao, T.; Li, Z.; Zhu, G.; Zou, X.; Chem. Mater. 2010, 22, 3316.

90. Reineke, T. M.; Eddaoudi, M.; O'Keeffe, M.; Yaghi, O. M.; Angew. Chem. Int. Ed. 1999, 38, 2590.

91. Dewa, T.; Saiki, T.; Aoyama, Y.; J. Am. Chem. Soc. 2001, 123, 502.

92. Wu, X.; Lin, Z.; He, C.; Duan, C.; New J. Chem. 2012, 36, 161.

93. Sen, R.; Saha, D.; Koner, S.; Catal. Lett. 2012, 142, 124.

94. Wu, P.; Wang, J.; Li, Y.; He, C.; Xie, Z.; Duan, C.; Adv. Funct. Mater. 2011, 21, 2788.

95. Evans, O. R.; Ngo, H. L.; Lin, W.; J. Am. Chem. Soc. 2001, 123, 10395

96. D'Vries, R. F.; Iglesias, M.; Sneijko, N.; Gutiérrez-Puebla, E.; Monge, A. M.; Inorg. Chem. 2012, 51, 11349.

97. D’Vries, R. F.; O’Shea, V. A. P.; Sneijko, N.; Iglesias, M.; GutiérrezPuebla, E.; Monge, A. M.; Cryst. Growth Des. 2012, 12, 5535.

98. Ren, Y.; Liang, J.; Lu, J.; Cai, B.; Shi, D.; Qi, C.; Jiang, H.; Chen, J.; Zheng, D.; Eur. J. Inorg. Chem. 2011, 4369.

99. Gándara, F.; García-Cortés, A.; Cascales, C.; Gómez-Lor, B.; GutiérrezPuebla, E.; Iglesias, M.; Monge, A.; Snejko, N.; Inorg. Chem. 2007, 46, 3475 .

100. Gándara, F.; Gutiérrez-Puebla, E.; Iglesias, M.; Proserpio, D. M.; Snejko, N.; Monge, A.; Chem. Mater. 2009, 21, 655

101. Bernini, M. C.; Gándara, F.; Iglesias, M.; Snejko, N.; Gutiérrez-Puebla, E.; Brusau, E. V.; Narda, G. E.; Monge, A.; Chem. Eur. J. 2009, 15, 4896.

102. Cunha-Silva, L.; Lima, S.; Ananias, D.; Silva, P.; Mafra, L.; Carlos, L. D.; Pillinger, M.; Valente, A. A.; Paz, F. A. A.; Rocha, J.; J. Mater. Chem. 2009, 19, 2618.

103. Vitorino, M. J.; Devic, T.; Tromp, M.; Férey, G.; Visseaux, M.; Macromol. Chem. Phys. 2009, 210, 1923. 